\title{
De effectiviteit van e-learning en de implementatie in het medisch onderwijs
}

\author{
M.E.W. Dankbaar
}

\section{Samenvatting}

E-learning wordt op diverse plekken ingezet in het medisch onderwijs. De vraag is of het leereffect ervan ook aangetoond kan worden en of dit vergelijkbaar is met bijvoorbeeld contactonderwijs. Aan de hand van een bespreking van twee omvangrijke meta-analyses, waarbij leereffecten van instructie met e-learning worden vergeleken met klassikale instructie, wordt de conclusie getrokken dat e-learning een volwaardig alternatief is voor klassikaal opleiden. Dit geldt voor instructievormen die zijn gericht op kennis, vaardigheden of gedrag; voor initiële opleidingen of werkplekopleiden; voor een breed (niet uitsluitend medisch) terrein. E-learning kan zelfstandig of aanvullend op contactonderwijs worden ingezet.

Tegen de achtergrond van deze positieve resultaten, en van de voordelen van e-learning voor de medische setting (flexibel, multimediaal leren, met standaardinhouden die voor iedereen toegankelijk zijn), is het opvallend dat e-learning niet intensiever wordt gebruikt. Aan de hand van een analyse van faal/succesfactoren voor implementatie worden aanbevelingen gedaan die betrekking hebben op de aansluiting van e-learning toepassingen op de omgeving en op het proces van implementatie. (Dankbaar MEW. De effectiviteit van e-learning en de implementatie in het medisch onderwijs. Tijdschrift voor Medisch Onderwijs 2009;28(5):212-222.)

\section{Inleiding}

E-learning wordt op diverse plekken ingezet bij medische opleidingen, omdat het een aantal belangrijke potentiële voordelen heeft. Het stelt de lerende in staat zelf te beslissen over waar en wanneer wordt geleerd en het verschaft directe feedback. Standaardleerinhouden zijn voor grote groepen beschikbaar en kunnen gemakkelijk up-to-date worden gehouden. Ook kunnen leerinhouden via tekst, beeld én geluid worden geïllustreerd. De meerwaarde van deze onderwijsvorm voor de medische opleidingen, waar het leren op de werkplek een belangrijke rol speelt, is aanzienlijk. Maar is e-learning ook een volwaardig alternatief voor contactonderwijs? Is het leereffect aangetoond en zo ja, is het vergelijkbaar met dat van contactonderwijs?

Deze vraag is relevant voor zowel de basisopleiding geneeskunde als voor de specialis- tische vervolgopleidingen. Wanneer e-learning een effectieve (en wellicht efficiëntere) onderwijsvorm is, is de vraag gerechtvaardigd hoe het komt dat deze methode doorgaans nog vrij beperkt wordt ingezet, in het bijzonder in de klinische context. Wat zijn belemmerende factoren en hoe kan de implementatie in de medische context worden bevorderd? Na een korte omschrijving van het begrip e-learning passeren in dit artikel deze vragen de revue.

\section{Het begrip e-learning}

Wat is e-learning? Het is een containerbegrip; oefenprogramma's, patiëntsimulaties of online groepsopdrachten zijn alle e-learning toepassingen. Een veel gehanteerde omschrijving voor e-learning is:

'een verzamelnaam voor het vormgeven van leersituaties (formeel en informeel) 
met behulp van informatie- en communicatietechnologie'. ${ }^{1}$

Rosenberg benadrukt de mogelijkheden om het informele leren te ondersteunen:

\section{'E-learning refers to the use of internet technologies to deliver a broad array of solutions that enhance knowledge and performance.' ${ }^{2}$}

Webbased Instructie en Online Leren zijn synoniemen van e-learning. Deze synoniemen worden door elkaar gebruikt. In dit artikel gebruiken we de term e-learning (EL), omdat deze in Nederland het meest voorkomt. Al sinds de jaren zestig worden computers ingezet in het onderwijs, voor tutorials (online opleidingsprogramma's) en toetsen. Hiervoor werden termen als Computer Assisted Instruction (CAI) en Computer Ondersteund Onderwijs (COO) gehanteerd. De voordelen van multimediale en interactieve leerinhouden en de mogelijkheid van registratie van de voortgang stimuleerden sinds de jaren tachtig het gebruik. Sinds het internettijdperk zijn de toepassingen steeds meer webbased geworden. De belangrijkste voordelen hiervan ten opzichte van $\mathrm{COO}$ zijn $^{3}$ :

- Communicatie op afstand tussen studenten onderling en met docenten is mogelijk (bijvoorbeeld met een discussieforum).

- Leerinhouden kunnen centraal up-todate worden gehouden en zijn tegelijk toegankelijk voor grote groepen.

- Voortgangsregistratie is centraal beschikbaar (managementinformatie).

De inzet van sociale software in het onderwijs bouwt hierop voort, met webapplicaties die samenwerken en informatiedelen ondersteunen, zoals wiki's (zie www.ecgpedia.org; een wiki over ECG's). De laatste jaren zijn 'blended learning' en 'mobile learning' sterk in opmars. Zie Figuur 1: een videoweergave van lichamelijk onderzoek op een smart Phone (een voorbeeld van mobile learning). Voor een begripsomschrijving zie Box 1.

Box 1. Toelichting begrippen.

- Sociale software maakt de online interactie tussen mensen mogelijk, faciliteert virtuele relaties, creëert virtuele omgevingen waar mensen samen kunnen werken of virtuele gemeenschappen kunnen vormen. In brede zin omvat de term verouderde media zoals e-mail en 'instant messaging', maar sommigen beperken de betekenis tot de recentere media, zoals 'blogs', 'wikis' en social bookmarking (bron: http://nl.wikipedia.org, 17-7-'09).

- Met het begrip 'wiki' wordt een verzameling van een bepaald type hypertextdocumenten aangeduid alsook de software die gebruikt wordt om deze te realiseren. Een wiki is een applicatie of (web)toepassing, waarmee webdocumenten gezamenlijk kunnen worden bewerkt. Een bekend voorbeeld van een wiki is Wikipedia. (bron: http://nl.wikipedia.org 17-7-'09).

- 'Blended learning' is een combinatie van e-learning met contactonderwijs.

- Onder 'mobile learning' wordt verstaan het leren met behulp van mobiele apparaten zoals smart phones, tablet pc's, etc.

\section{Onderzoek naar de effectiviteit van e-learning}

Sinds de jaren zestig zijn er veel artikelen verschenen over CAI en (vanaf de jaren negentig) over EL. De meerderheid van deze artikelen (ca. 60\%) is beschrijvend van aard, zonder een evaluatie onder gebruikers of een onderzoek naar de effectiviteit. ${ }^{4-5}$ Dit komt onder andere omdat technologie zich snel blijft ontwikkelen; het blijft dan relevant innovatieve concepten te beschrijven en ideeën te delen met vakgenoten. Om goed onderzoek te kunnen doen naar het effect van technologie in het onderwijs is bovendien niet alleen geld nodig maar ook specifieke kennis en vaardigheden. Het is van belang voor de ontwikkeling van het vakgebied om voor een brede groep professionals regelmatig te publiceren over effect- of evaluatiestudies en budgetten in te zetten voor onderzoek naar e-learning interventies. 


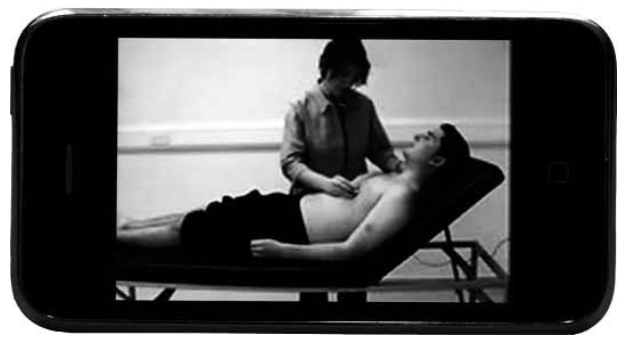

Figuur 1. Videoweergave van lichamelijk onderzoek op een smartphone (bron: Youtube).

Wat komt er uit het vergelijkende onderzoek dat wel is uitgevoerd? $\mathrm{Bij} 40 \%$ van de artikelen die evaluatief van aard zijn, gaat het in de loop der jaren om een groot aantal studies. In het kader van dit artikel zullen de resultaten worden besproken aan de hand van twee omvangrijke review-studies van Sitzmann et al. en Cook et al.:

- Een meta-analyse naar de effectiviteit van EL bij studenten en cursisten in het algemeen. $^{6}$

- Een meta-analyse naar de effectiviteit van EL bij studenten en cursisten in de gezondheidszorg. ${ }^{7}$

Sitzmann en Cook et al. gebruiken in deze studies de term Webbased Instruction. We nemen juist deze reviewstudies als basis omdat ze vrij recent zijn (2006 en 2008), gebaseerd zijn op grote aantallen studies, selecteren op methodologische kwaliteit en een breed terrein beslaan.

\section{Effectiviteit van e-learning versus klassikaal leren in de algemene context}

In de meta-analyse van Sitzmann et al. stonden de volgende vragen centraal:

- Is EL even effectief als Classroom/ Face-to-face Instruction (CI)?

- Welke instructiekenmerken zijn bepalend voor de effectiviteit?

Op basis van een literatuursearch (trefwoorden: web, learn, outcome, reaction, etc.) werden 3.461 studies gevonden in de periode 1991-2005. Na een selectie (criteria: studie is relevant voor de vraagstelling, heeft betrekking op universitair onderwijs of werkgericht opleiden, is Engelstalig) bleven er 96 studies over, zowel wel als niet gerandomiseerd. Gezamenlijk hadden deze 96 onderzoeken betrekking op 19.000 deelnemers en 168 cursussen waarin 'college students' of werknemers via EL of CI kennis of vaardigheden verwierven over een breed domein (van psychologie tot technische onderwerpen). Wat betreft de leereffecten werd bij deze meta-analyse onderscheid gemaakt tussen declaratieve kennis (feiten en principes kennen) en procedurele kennis (weten hoe een taak moet worden uitgevoerd). De studies werden gecodeerd op onderzoeksdesign (wel/niet gerandomiseerd) en op instructiekenmerken zoals gebruikte instructiemethode (lezing, instructie, video, tekstboek), trainingslengte, mate van controle door deelnemers (over inhoud, volgorde, tempo), mate van persoonlijke interactie (met medestudenten, docent), oefeningen en feedback.

Is EL even effectief als CI?: Uit de metaanalyse blijkt dat EL even effectief is als CI in het onderwijzen van zowel declaratieve als procedurele kennis, mits gecontroleerd wordt op de instructiemethode. EL met CI (blended learning) is wat effectiever dan alleen CI, zowel bij declaratieve kennis als bij procedurele kennis. Studenten zijn even tevreden met EL als met CI.

Welke instructiekenmerken zijn bepalend voor de effectiviteit bij EL?: De volgende kenmerken hebben een (enigszins) positief effect op de leerresultaten: veel controle op de cursus, oefenmogelijkheid, feedback en meer trainingsdagen. De mate van interactie (met studenten of docenten) heeft geen invloed. De auteurs signaleren dat in de studies de instructiekenmerken beperkt gedefinieerd worden. ${ }^{6}$ 
Effectiviteit van e-learning versus klassikaal leren in de gezondheidszorg

In de meta-analyse van Cook et al. stonden de volgende onderzoeksvragen centraal:

- Leidt EL tot betere leerresultaten dan geen interventie?

- Leidt EL tot betere resultaten dan traditionele instructievormen?

- Welke instructiekenmerken spelen een rol?

$\mathrm{Na}$ een literatuursearch (trefwoorden: web, e-learning, outcome, comparative study, etc.) over de periode 1990-2007 kwam men uit op 2200 studies binnen de gezondheidszorg. Na selectie (criteria: studie is relevant voor vraagstelling, heeft betrekking op de gezondheidszorg, op opleiden binnen onderwijsinstellingen en in werkverband, in diverse talen) bleven er 201 studies over, zowel wel als niet gerandomiseerd. In totaal hadden de studies betrekking op 26.000 deelnemers ('health care students' en 'workers/ medici'). De typen interventies uit de studies waren: tutorials, virtuele patiëntenprogramma's, online discussies met peers/docenten (bij EL), klassikale/face-to-face instructie, schriftelijke cursussen en blended learning. De effectmetingen hadden betrekking op de tevredenheid van de cursist, het kennisen vaardigheidsniveau (gemeten in testsettings) en op het gedrag (gemeten in de praktijk). Ook hier werden de studies gecodeerd op onderzoeksdesign en instructiekenmerken: veel of weinig interactie, oefenmogelijkheid, toegangsduur, cursuslengte ( $<$ of $>1$ week), wel/geen online discussie (bij EL), etc. Ook werd gecodeerd op de setting (klas/werkomgeving) en op de wijze waarop het eindresultaat werd beoordeeld (subjectief/objectief).

Leidt EL tot betere leerresultaten dan geen interventie?: Uit de resultaten van deze meta-analyse komt naar voren dat in vergelijking met geen interventie er een sterk positief effect blijkt te bestaan bij EL in- terventies die zich richten op verbetering van kennis, vaardigheden of gedrag. Wel en niet gerandomiseerde studies laten ongeveer dezelfde resultaten zien. Dit lijkt vanzelfsprekend, maar het is een belangrijk startgegeven, omdat hiermee wordt aangetoond dat EL effectief is op een breed terrein. Een vergelijking met andere interventies is methodologisch ook altijd gecompliceerder (zie verder).

Leidt EL tot betere resultaten dan traditionele instructievormen?: In vergelijking met traditionele methoden (contact- of schriftelijk onderwijs) is EL even effectief. Bij kennisgerichte interventies doet de EL variant het iets beter, maar dit blijkt veroorzaakt te worden door de combinatie van EL en CI. Ook bij vaardigheids- en gedragsgerichte interventies is er geen verschil in effectiviteit tussen EL en CI; dit geldt voor gerandomiseerde en voor nietgerandomiseerde studies. Deelnemers zijn net zo tevreden over webbased als over traditionele onderwijsmethoden. Cook et al. signaleren wel 'inconsistencies across studies' (geen 100\% consistent beeld per studie).

Welke instructiekenmerken spelen een rol bij EL?: Bij de kennisgerichte interventies hebben online discussies en langere cursussen een positief effect; de andere kenmerken maken geen verschil. Bij de overige interventies is het aantal studies te klein om conclusies te trekken. ${ }^{7}$

\section{Conclusies uit het effectiviteits- onderzoek}

Wanneer we de resultaten van de beide meta-analyses vergelijken (samen bijna 300 studies), valt op dat deze grote overeenkomsten vertonen. De gemeenschappelijke conclusie luidt: met EL kunnen leerresultaten worden bereikt die vergelijkbaar zijn met die van traditionele methoden. Dit geldt voor instructievormen die betrekking 
hebben op kennis, vaardigheden en gedrag. EL is dus een volwaardig alternatief voor contactonderwijs. Ook in vele andere overzichtsstudies wordt de conclusie getrokken dat EL (minimaal) net zo effectief is als traditioneel onderwijs. ${ }^{8-9}$ Voor het leren van (declaratieve en procedurele) kennis leidt een 'blended' ontwerp tot een beter resultaat dan alleen klassikale instructie. Studenten/cursisten zijn even tevreden met EL als met klassikale instructie; daarbij maakt het niet uit of ze zelf de methode kiezen of deze toegewezen krijgen.

Wat betreft de effecten van instructiekenmerken is er een inconsistent beeld. Bij sommige interventies hebben oefeningen, feedback en online discussies een positief effect, bij andere niet. Dit kan samenhangen met het feit dat de instructiekenmerken vaak summier beschreven worden in de studies en leerresultaten verschillend worden gemeten. ${ }^{7}$ Uit onderzoek naar de effectiviteit van feedback is bekend dat zowel aanwijzingen over een taak in de vorm van video- of audio-fragmenten als feedback bij EL effectief zijn voor leren. ${ }^{10}$ Ook het positieve effect van oefeningen is bekend uit eerder onderzoek. ${ }^{11}$ Er is meer onderzoek nodig om de optimale mix van instructiekenmerken in een online leeromgeving te bepalen.

Een medium op zichzelf zorgt dus niet voor effectief leren; de effectiviteit wordt bepaald door de instructiekenmerken en inhoud. Clark trok deze conclusie al in de jaren 80. ${ }^{12-13}$ Friedman wees in 1994 nog eens op de beperkingen van het mediavergelijkend onderzoek. Volgens hem is het methodologisch erg lastig om de vraag te stellen of EL beter werkt dan CI, omdat dat altijd zal afhangen van de kwaliteit van de interventies. Bovendien zijn er vaak specifieke redenen om een medium te kiezen; deze unieke kenmerken maken vergelijking per definitie moeilijk. Fried- man benadrukt in 1994 de noodzaak om ontwerpkeuzes en instructiemodellen te onderzoeken. ${ }^{14}$ Vijftien jaar later wordt dit type onderzoek nog weinig uitgevoerd. Het is dus voor de komende jaren van belang meer onderzoek te doen naar de vraag wanneer e-learning kan worden ingezet en hoe.

Regelmatig wordt gerapporteerd dat studenten met EL efficiënter leren dan met traditionele methoden en het geleerde ook beter onthouden. ${ }^{8}$ Meestal komt dat door inzet van specifieke instructiekenmerken, die gemakkelijker met EL zijn te realiseren dan met CI. ${ }^{7}$ Wanneer studenten bijvoorbeeld met EL zelf het tempo van een leersessie kunnen bepalen, is het logisch dat ze (gemiddeld) minder tijd besteden aan het leren van de inhoud dan wanneer ze in een collegezaal iets leren. Of wanneer ze zelf online een anatomische voorstelling kunnen manipuleren (vergroten/verkleinen, draaien), is het logisch dat ze dit eerder (en beter) begrijpen dan wanneer dit in een boek of college wordt uitgelegd. Niet het medium is dan de oorzaak van het efficiënter leren, maar de onderliggende instructiekenmerken (de zelfcontrole door de student respectievelijk de dynamische visualisering van de leerinhoud).

De hoofdconclusie dat met EL even goede leerresultaten kunnen worden bereikt als met traditionele instructiemethoden blijkt breed en consistent te gelden: in het medische en niet-medische domein, voor opleidingen en leren op de werkplek, bij een breed scala aan onderwerpen, bij verschillende typen leerresultaten (kennis, vaardigheden, gedrag) en bij cursisten met verschillende achtergronden. EL is dus een volwaardig alternatief voor klassikaal opleiden en kan zelfstandig of aanvullend op andere methoden worden ingezet. Bij goed gebruik van instructiekenmerken kan het ook leiden tot efficiënter leren. 


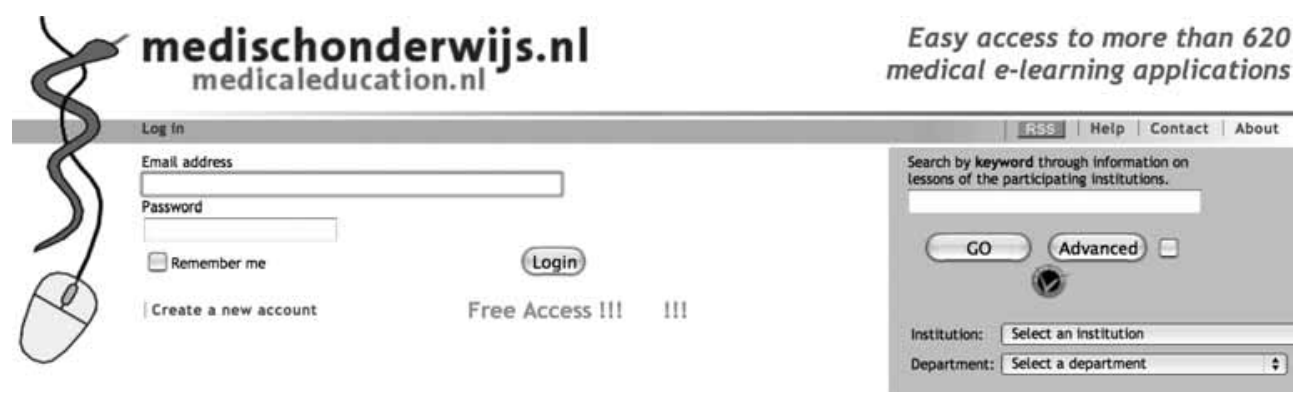

Figuur 2. www.medischonderwijs.nl, de portal van de Nederlandse UMC's.

Dit is een conclusie die veel impact heeft voor het ontwerpen van leertrajecten in het medisch onderwijs, waar klassikale en faceto-face instructie nog steeds dominant zijn.

\section{Implementatie van e-learning in het medisch onderwijs}

Berman et al. stellen dat EL in de VS over de hele linie van het medisch onderwijs relatief matig wordt gebruikt, maar vooral weinig in de klinische context.We hebben de indruk dat deze constatering ook opgaat voor Nederland. Gezien de bovenstaande conclusie is dat opmerkelijk. Voor de mate van implementatie van EL in het onderwijs kunnen we onderscheid maken tussen ontwikkeling (inclusief beschikbaarstelling) van EL toepassingen, gebruik (in het curriculum) en integratie (verankering in het curriculum). ${ }^{15}$ In het universitair medisch onderwijs is een vrij grote hoeveelheid EL toepassingen aanwezig, die ontwikkeld is door de verschillende opleidingen geneeskunde en beschikbaar is via de portal MedischOnderwijs.nl van de gezamenlijke UMC's (> 1000 titels, ca. 600 zijn toegankelijk voor iedereen; zie Figuur 2). De hoeveelheid ontwikkelde toepassingen en het gebruik wisselen sterk per faculteit. Ook blijkt dat het gebruik vaak beperkt blijft tot de eigen faculteit. ${ }^{16}$

Bij het Erasmus MC wordt 15 à 20\% van de zelfstudieopdrachten in de bachelorfase ingevuld met EL programma's; dit komt neer op gemiddeld (over drie jaar) ca. 3,5 uur per week. Studenten gebruiken de programma's vrij intensief (bijna driekwart van de eersteen tweedejaars studenten van een curriculumonderdeel heeft alle EL programma's gedaan); vooral de programma's over complexe onderwerpen (genetica, besliskunde) en technische basisvaardigheden die worden getoetst voor het coschap. ${ }^{17}$ Wanneer studenten worden beoordeeld op kennis van de inhoud van de programma's verhoogt dit het gebruik sterk; een effect dat ook in onderzoek is aangetoond. ${ }^{18}$ Uit evaluaties blijkt dat studenten de EL programma's (zeer) positief waarderen; de flexibele beschikbaarheid, het multimediale karakter en de interactieve vragen vinden ze erg leerzaam. ${ }^{19}$

Tijdens de klinische fase en de medische vervolgopleidingen is de implementatie van EL aanzienlijk minder. Dat is opmerkelijk, aangezien juist in de klinische praktijk EL een aantal belangrijke voordelen biedt (zoals het 'just in time' voorbereiden van risicovolle handelingen). Studenten en artsen in opleiding tot specialist (aios) moeten zich dan veel nieuwe kennis en vaardigheden eigen maken en er is weinig tijd beschikbaar bij de staf om dit alles goed te begeleiden.

Wat zijn belangrijke drempels binnen de medische opleidingen en hoe kan de implementatie van EL worden gestimuleerd? 


\section{Implementatiefactoren}

De factoren die bij de implementatie een rol spelen, komen overeen met de factoren die bij algemene onderwijs- of organisatievernieuwingen een rol spelen. Er kan onderscheid worden gemaakt tussen factoren die betrekking hebben op de aansluiting van de vernieuwing op de omgeving en factoren die samenhangen met het proces van implementatie. ${ }^{20}$ Hieronder worden deze factoren verder uitgewerkt en wordt hun betekenis voor (met name) de klinische context geanalyseerd, met praktische richtlijnen voor verbetering.

\section{Factoren die betrekking hebben op de mate waarin het programma aansluit op de omgeving}

- Noodzaak: Is er een duidelijk probleem, behoefte of noodzaak voor de (EL) toepassing? Is er een duidelijke meerwaarde en wordt dit onderkend in de organisatie? Zeker in de beginfase van invoering is het belangrijk onderwerpen (of voordelen) te kiezen die belangrijk zijn voor de organisatie en een herkenbaar probleem oplossen. Dit kan ook worden vertaald in een business case (welke resultaten worden gerealiseerd, voor wie en tegen welke kosten). Vaak wordt met EL een kostenbesparing gerapporteerd, zoals minder docenturen en verlettijd. ${ }^{8}$ Het is niet gemakkelijk de kosten van een nieuwe methode te vergelijken met bestaande methoden, omdat de kosten van de laatste vaak erg impliciet zijn. Wanneer klassikaal opleiden geen optie is, is het soms zinvoller na te gaan wat de kosten (voor de patiëntenzorg) zijn van niet opleiden, Als de noodzaak wel wordt erkend, kan men ook twijfelen over de effectiviteit van EL als methode. Berman stelt dat dit een belangrijke barrière is voor gebruik. Door de jarenlange onderzoeken naar de vraag of EL effectiever is dan klassikaal leren, en de methodologische haken en ogen hierbij, is er een gebrek aan duidelijkheid over de effectiviteitsvraag. Zijn conclusie is dat we moeten ophouden met dit type onderzoek omdat duidelijk is dat EL net zo effectief is; we moeten ons richten op de vraag wanneer we EL inzetten en hoe. ${ }^{15}$ Communicatie over de effectiviteit en het tonen van 'best practices' kunnen het gevoel van noodzaak versterken. ${ }^{21}$

- Consistentie: Is er een samenhang tussen het overige strategische beleid, de gehanteerde onderwijsvisie en de organisatie? Sluiten de toepassingen aan bij de cultuur en werkprocessen van gebruikers? Hier ligt vaak een belangrijke drempel: voor de ontwikkeling van EL toepassingen is het noodzakelijk leerdoelen en inhouden expliciet te maken. In de klinische context is doorgaans sprake van een impliciete leercultuur, hoewel op dat gebied met de huidige vernieuwing van de vervolgopleidingen, veel veranderingen gaande zijn. Deze verandering brengt een meer gestructureerde wijze van opleiden met zich mee; de implementatie van EL zal dan waarschijnlijk gemakkelijker verlopen. Het lijkt logisch goede voorbeelden te ontwikkelen bij opleidingen die hierin voorop lopen. Berman ziet de slechte aansluiting tussen EL ontwikkelaars en opleiders ook als een belangrijke barrière. ${ }^{15}$ De ontwikkeling van EL toepassingen vereist een goede samenwerking tussen opleiders en ontwikkelaars. Dat is een ander soort samenwerking dan met uitgevers; veel docenten zijn nog niet zo bekend met het ontwikkelproces en de technische mogelijkheden bij EL. Ontwikkelaars spreken vaak een andere taal dan docenten. Het helpt om vooraf de werkwijze, met voorbeelden, goed te beschrijven. Tot slot is het voor een 
opleidingsdirecteur soms lastig een 'passende' keuze te maken uit het EL aanbod. Objectieve kwaliteitsindicatoren ontbreken en het vraagt kennis om snel tot een goed oordeel te komen. Voor verankering van EL toepassingen in het curriculum dienen deze wel te passen in de opleidingsvisie. ${ }^{9}$ Ontwikkeling van kwaliteitscriteria, goede advisering bij de selectie en evaluatie onder gebruikers kunnen deze onzekerheid wegnemen.

- Nabijheid: Ligt het gebruik of de ontwikkeling van EL toepassingen binnen bereik? Is de technische infrastructuur geschikt, sluiten de toepassingen aan op de competenties en de situatie van betrokkenen? Is de tijd die het kost vrij te maken? Opleiders of docenten kunnen bijvoorbeeld de meerwaarde van online toetsing wel erkennen, maar de tijdsinvestering te groot vinden om deze toetsen te ontwikkelen of zich niet capabel achten om goede toetsvragen te maken. Tijdens een 'Good Practice' middag over EL bij het Erasmus MC bleek een derde van de aanwezige docenten de vereiste kennis en vaardigheden bij EL als belangrijkste bezwaar te zien. Dit bezwaar scoorde hoger dan 'geen persoonlijk contact met studenten' (22\%), 'gebruik vereist gemotiveerde studenten' (19\%) en 'EL heeft geen meerwaarde' en 'vraagt investeringen' (beide 13\%), $\mathrm{n}=55$. Docentprofessionalisering en facilitering van docenten kunnen deze bezwaren wegnemen.

\section{Factoren die samenhangen met het proces van implementatie}

- Sturing: Staat de implementatie van effectieve opleidingsmethoden op de bestuurlijke agenda? Wordt er gestuurd op resultaat en is er aandacht voor gebruik? Zijn er voldoende middelen? Het eigen maken en inbedden van een nieuwe manier van opleiden kost tijd. Regie en facilitering zijn hierbij kernelementen. Sturing wordt gemakkelijker gemaakt wanneer er een EL beleidsplan is, op basis waarvan het management kan kiezen en overzicht krijgt, en wanneer het management kennis heeft van de mogelijkheden van EL.

- Betrokkenheid: De betrokkenheid van opleiders/docenten en studenten/aios is vanzelfsprekend belangrijk. De opleiders weten het beste waar de knelpunten zitten. Betrek hen bij de plannen en zorg ook voor draagvlak bij de 'opinion leaders'. Binnen het Erasmus MC hebben we goede ervaringen met een werkgroep EL, waarin onderwijscoördinatoren, een studentenvertegenwoordiger en EL ontwikkelaars samen ervaringen delen en plannen maken.

- Begeleiding: Bij inzet van technologie in het onderwijs zijn er regelmatig technische uitdagingen. Ondersteun de 'early adopters' die de kinderziektes tegenkomen actief, 'pamper' hen en wees pro-actief in het oplossen van knelpunten. Stimuleer de ontwikkeling van ICT en EL kennis bij de staf door scholing, onder andere gebruik makend van EL als methode ('teach as you preach').

- Communicatie: Laat zien waar de meerwaarde ligt, wat goed werkt (de successen!) en wat niet. Laat verschillende toepassingen zien. Besteed de meeste energie aan de opleiders die graag mee willen doen.

\section{Van faal- naar succesfactoren}

Wanneer een of meer van deze zeven factoren gebrekkig aanwezig zijn, vormen ze feitelijk faalfactoren. We kunnen ze visualiseren als dimensies die een stimulerend of belemmerend effect op de implementatie van EL hebben (zie Figuur 3). Het is wenselijk onderzoek te doen naar het (relatieve) belang van deze factoren bij verschillende 


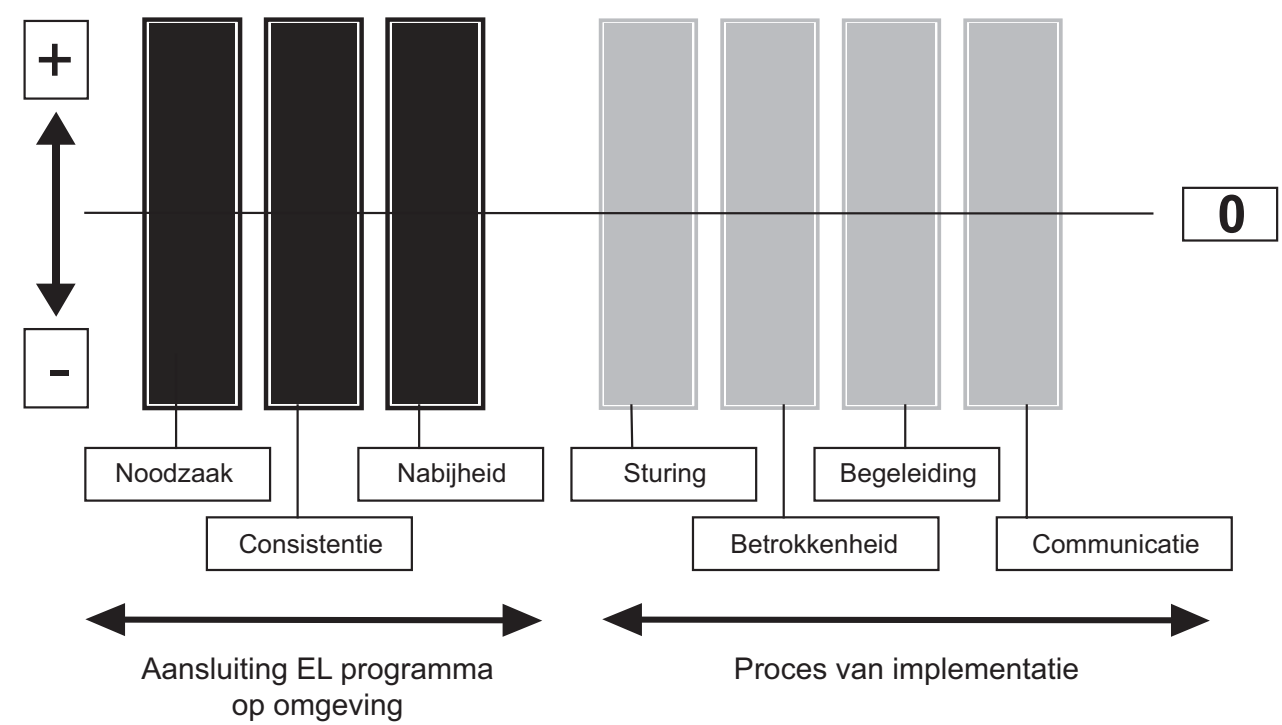

Figuur 3. Succes-Ifaalfactoren bij de implementatie van e-learning.

typen toepassingen. Berman heeft onderzocht hoe implementatiefactoren bij virtuele patiëntprogramma's doorwerken op studenttevredenheid tijdens coschappen. Zijn conclusie: hoe meer de EL programma's zijn geïntegreerd in het curriculum (goede introductie, intensief gebruik van de casus tijdens het hele coschap ten koste van andere leeractiviteiten, scholing van opleiders en integreren van casus in de beoordeling) hoe hoger de tevredenheid van studenten en het gepercipieerde leereffect. $^{23}$

\section{Conclusies}

E-learning is een effectief medium voor opleiden, waarbij de leereffecten in brede zin vergelijkbaar zijn met traditionele methoden. Het kan aanvullend of zelfstandig worden ingezet voor de ondersteuning van formeel opleiden of informeel leren op de werkplek. In de medische opleidingen, waar werkplekleren dominant is en klassikale trainingen vaak te weinig flexibel zijn, is EL een krachtig medium waarmee de efficiëntie van opleiden sterk kan worden vergroot. Opleiden en leren in de zorg moet efficiënter, zeker in de klinische setting. De eisen met betrekking tot patiëntenzorg worden hoger, de hoeveelheid kennis en nieuw te leren vaardigheden nemen sterk toe en er is weinig tijd beschikbaar bij de staf om dit alles goed te begeleiden. Dat betekent dat de klassieke concepten van opleiden niet meer voldoen als dominant model.

De implementatie van EL is nog beperkt, zeker in de klinische context. Deze kan worden versterkt door aansluiting te zoeken op herkenbare opleidingsproblemen en bestaande (vernieuwings)plannen en goede aandacht te geven aan professionalisering en ondersteuning van opleiders/ docenten. In het proces van implementatie zijn regievoering en facilitering door het management belangrijk, evenals het creëren van betrokkenheid bij opleiders en goede communicatie over de resultaten.

Het onderzoeksgebied van EL is nog jong. De hoofdconclusies met betrekking tot de effectiviteit zijn duidelijk, maar er 
ligt nog een terrein braak van ontwerp- en implementatievraagstukken. Hier is verder onderzoek wenselijk.

\section{Dankwoord}

De auteur dankt drs. M. Doets (Erasmus MC), drs. P.M. Bloemendaal (LUMC) en drs. W.P.M Hols (UMCU), voor hun kritische review van het artikel.

\section{Literatuur}

1. Rubens W. Omzien in verwondering: de (prille) geschiedenis van e-learning? In: E-learning: meerwaarde of meer van hetzelfde? HRD Thema 2003;4 (3),9-17. [Looking back and wondering: the (early) history of e-learning? HRD Thema 2003; 4(3),9-17].

2. Rosenberg M. E-learning: strategies for delivering knowledge in the digital age. New York: Mc Graw Hill; 2001, p. 28.

3. Dankbaar M, Droste J, van Hoek F. Het kiezen van een elektronische leeromgeving. Opleiding \& Ontwikkeling 2003; 7/8:17-20. [Selecting an electronic learning environment. Education \& Development 2003;7/8:17-20].

4. Adler M, Johnson K. Research report. Quantifying the literature on computer-aided instruction in medical education. Acad Med 2000;75(10):1025-8.

5. Chumley-Jones H S, Dobbie A, Alford C L. Webbased learning: Sound educational method or hype? A review of the evaluation literature. Acad Med 2002;77 (10 Suppl):S86-93.

6. Sitzmann T, Kraiger K, Stewart D, Wisher R. Comparative effectiveness of webbased and classroom instruction: a meta-analyses. Personnel Psychology 2006;59:623-653.

7. Cook D, Levinson A, Garside S, Dupras D, Erwin P, Montori V. Internet-based learning in the health professions, a meta-analysis. JAMA 2008;10:11811196.

8. Ruiz MJG, Mintzer, MJ, Leipzig RM. The impact of E-Learning in medical education. Acad Med 2006;3:207- 212.

9. Bates T. Managing technological change, strategies for College and University leaders. San Fransisco: Jossey Bass; 2000.

10. Hattie J, Timperley H. The power of feedback. Review of Educ Research 2007;77(1):81-112.

11. Norman G. The end of educational science? Adv in Health Sci Educ 2008;13:385-389.

12. Clark RE. Reconsidering research on learning from media. Review of Educ Research 1983;53:445-460.

13. Clark RE. Media will never influence learning. Educ Technology Research and Development 1994;42: 21-29.
14. Friedman CP. The research we should be doing. Acad Med 1994;6:455-457.

15. Berman NB, Fall LH, Maloney CG, Levine DA. Compter-assisted instruction in clinical education: a roadmap to increasing CAI implementation. Adv in Health Sci Educ 2008;13:373-383.

16. Bloemendaal PM, Eggermont S, Baalen van JM. MedicalEducation.nl: A national repository for Elearning in The Netherlands. 19th Slice of Life Conference 2007, Workshop, 147. 6-30-2007.

17. Dankbaar MEW, Lange JF. De rol van e-learning bij het leren van klinische vaardigheden. Opleiding \& Ontwikkeling, 2008, no 12: blz 14-17. [The role of e-learning in clinical skill training. Education \& Development 2008, no.12: p14-17].

18. McNulty JA, Halama J. Dauzvardis MF, Espiritu B. Evaluation of web-based computer-aided instruction in a basic science course. Acad Med 2000;75:59-65.

19. Dankbaar M, Doets M, deMan R. Rapportage Elearning activiteiten, juli '09 (intern doc. Erasmus MC). [Report on E-learning activities, july 2009 (internal document Erasmus MC)].

20. St.SURF. Succesfactoren voor instellingsbrede implementatie van ICT in het onderwijs, 2005. [Success factors for the implementation of ICT in education, 2005].

21. Rosenberg M. Beyond E-learning. San Fransisco: Pfeiffer; 2006.

22. Dankbaar M. Evaluatieresultaten Studiemiddag Best practices E-learning, juli '09 (intern doc.) Erasmus MC. Evaluation results - Study afternoon. Best practices in E-learning, july 2009 (internal document) Erasmus MC].

23. Berman N, Fall L, Smith S, Levine D, Maloney C, Potts M, Siegel B, Foster-Johnson L. Integration strategies for using virtual patients in clinical clerkships. Acad Med 2009;84 (7):942-949.

De auteur:

Drs. M.E.W. Dankbaar is programmamanager e-learning aan het Erasmus MC en voorzitter van de werkgroep e-learning van de NVMO.

Correspondentieadres:

Mw. drs. M.E.W. Dankbaar, Erasmus MC Desiderius school (voorheen het Opleidingsinstituut Geneeskunde), postbus 2040, 3000 CA Rotterdam. Tel.: 010- 7038161; e-mail:m.dankbaar@erasmusmc.nl

Belangenconflict: geen gemeld

Financiële ondersteuning: geen gemeld 


\section{Summary}

E-learning (or Webbased Instruction) is currently used in various domains of medical education. The question is whether it has demonstrable learning effects and whether the results are comparable with those of face-to-face methods. Based on the results of two meta-analyses comparing learning effects of e-learning and classroom-based approaches, we conclude that e-learning has outcomes that are comparable with those of classroom-based teaching. This conclusion applies to education aimed at knowledge, skills or behaviour, preclinical education and workplace-based education as well as to a broad, not exclusively medical, domain. E-learning can be used as the main educational approach or as a supplement to face-to-face instruction. In vieuw of these findings and the known advantages of e-learning for the clinical setting (flexibility, use of multimedia, standardisation of content, accessibility) it seems surprising that e-learning is not applied more extensively. Based on analysis of factors that determine success and failure of e-learning, recommendations are made for adaptation of e-larning applications to medical learning environments and for the implementation of e-larning methods. (Dankbaar MEW. The effectiveness of e-learning and its implementation in medical education. Dutch Journal of Medical Education 2009;28(5):212-222.) 